\title{
GENERAL EQUILIBRIUM WITH BANKS AND THE FACTOR-INTENSITY CONDITION
}

Emanuel R. Leão

Pedro R. Leão

J unho 2008

WP n 2008/63

DOCUMENTO DE TRABALHO

WORKI NG PAPER 
Emanuel R. Leão ${ }^{1}$

Pedro R. Leão ${ }^{2}$

WP no 2008/63

Junho de 2008

Abstract

1. INTRODUCTION

2. THE MODEL

3. THE FACTOR-INTENSITY CONDITION 27

4. REVERSING THE FACTOR-INTENSITY CONDITION 8

5. WHY ARE THE RESPONSES OF SECTORAL OUTPUTS NOT DEPENDENT UPON

THE FACTOR-INTENSITY CONDITION?

6. CONCLUSION

REFERENCES

ANNEXES

${ }^{1}$ Departament of Economics, Instituto Superior de Ciências do Trabalho e da Empresa and Dinâmia Centro de Estudos sobre a Mudança Socioeconómica, Avenida das Forcas Armadas, 1649-026 Lisboa, Portugal, Phone: 00351217903236, Fax: 00351217903933 - E-mail: emanuel.leao@iscte.pt

2 Department of Economics, Instituto Superior de Economia e Gestão, Technical University of Lisbon and UECE, Rua Miguel Lupi, No 20, 1200 Lisboa, Portugal - E-mail: pleao@iseg.utl.pt 


\section{General Equilibrium with Banks and the Factor-Intensity Condition*}

\section{Abstract}

This paper looks at the role played by the factor-intensity condition in the model developed by Leao (2003). To do this, we examine how the model reacts when the factor-intensity condition is reversed so that the banking industry ceases to be the capital intensive sector and becomes the labour intensive sector. Simulation results show that, in general, the qualitative nature of the results does not change. However, there two cases where the qualitative results are affected: the response of the real wage and of the labour supply to a shock in the banks technological parameter. We present an interpretation for these results based in part on the framework devised by Heckscher and Ohlin. We conclude that the factor-intensity condition does play a significant role in the model of Leao (2003).

Keywords: general equilibrium, banking industry, factor-intensity condition, Heckscher-Ohlin framework, sectoral shocks, allocation of capital and work hours between sectors.

JEL classification: E17, E22, E24, E32.

\footnotetext{
* We have received helpful comments from Mário Olivares. They are in no way responsible for
} our interpretations or any errors that the paper may contain. 
General Equilibrium with Banks and the Factor Intensity Condition

\section{Introduction}

Leao (2003) develops a model with two sectors - output sector and banking sector - and two factors of production in each sector (physical capital and labour effort). With the parameters used in his work, the banking sector is the capital intensive sector. In the present paper, we examine the role of the factor-intensity condition in his model: we change the parameters of the model so that the output sector becomes the capital intensive sector and we then make simulation experiments to see if this implies any significant modification to the results. We conclude that, in general, the qualitative results do not change when the banking industry ceases to be the capital intensive industry and becomes the labour intensive industry. There is, however, one interesting qualitative change: the response of the real wage and of the labour supply to a technological improvement in banks. After showing the simulation results and pointing out the difference, we present an interpretation based on the framework devised by Heckscher and Ohlin.

\section{The Model}

In the model of Leao (2003), there are households, firms and banks. The typical household's utility function is denoted $u\left(c_{t}, 1-n_{t}^{s}\right)$, where $c_{t}$ is consumption and $n_{t}^{s}$ is labour supply. The typical firm's production function is written $y_{t}=A_{t} F\left(k_{t}, n_{t}^{d}\right)$, where $y_{t}$ is real output, $A_{t}$ is a technological parameter, $k_{t}$ is the capital stock and $n_{t}^{d}$ is labour demand. The typical bank's production function is given by $b_{t}^{s}=D_{t}\left(k_{t}^{b}\right)^{1-\gamma}\left(n_{t}^{b}\right)^{\gamma}$, where $b_{t}^{s}$ is the bank's supply of credit in

real terms, $D_{t}$ is a technological parameter, $k_{t}^{b}$ is the stock of capital of the bank and $n_{t}^{b}$ is the number of work hours hired by the bank.

ISCTE - Instituto Superior de Ciencias do Trabalho e da Empresa, 


\section{General Equilibrium with Banks and the Factor Intensity Condition}

Households borrow from banks and then use the money thus obtained to buy goods from firms. There are five markets: goods market, labour market, bank loans market, firm shares market and bank shares market. As can be seen on page 157 of his paper, the competitive equilibrium is given by the following set of equations:

$$
u_{1}\left(c_{t}, 1-n_{t}^{s}\right)=\lambda_{t}
$$

$$
u_{2}\left(c_{t}, 1-n_{t}^{s}\right)=\beta E_{t}\left[\lambda_{t+1}\right] \frac{w_{t}}{1+E_{t}\left[\tilde{p}_{t+1}\right]}
$$

$$
\lambda_{t}=\beta E_{t}\left[\lambda_{t+1}\right] \frac{1+R_{t}}{1+E_{t}\left[\tilde{p}_{t+1}\right]}
$$

$$
\frac{b_{t+1}}{1+R_{t}}=c_{t}
$$

$$
A_{t} F_{2}\left(\bar{k}_{t}, \bar{n}_{t}^{d}\right)=w_{t}
$$

$$
E_{t}\left[A_{t+1}\right] F_{1}\left(\bar{k}_{t+1}, E_{t}\left[\bar{n}_{t+1}^{d}\right]\right)+(1-\delta)=\frac{1+E_{t}\left[R_{t+1}\right]}{1+E_{t}\left[\tilde{p}_{t+1}\right]}
$$

Tel. 217938638, Fax 217940042, E-mail: dinamia@iscte.pt, Internet: www.dinamia.iscte.pt 
General Equilibrium with Banks and the Factor Intensity Condition

$$
\begin{gathered}
R_{t} D_{t} \gamma\left(\bar{k}_{t}^{b}\right)^{1-\gamma}\left(\bar{n}_{t}^{b}\right)^{\gamma-1}=w_{t} \\
E_{t}\left[R_{t+1}\right] E_{t}\left[D_{t+1}\right](1-\gamma)\left(\bar{k}_{t+1}^{b}\right)^{-\gamma}\left(E_{t}\left[\bar{n}_{t+1}^{b}\right]\right)^{\gamma}+\left(1-\delta_{B}\right)= \\
=\frac{1+E_{t}\left[R_{t+1}\right]}{1+E_{t}\left[\tilde{p}_{t+1}\right]} \\
\frac{z_{t+1}^{f}=\frac{1}{H}}{1+R_{t}}=D_{t}\left(\bar{k}_{t}^{b}\right)^{1-\gamma}\left(\bar{n}_{t}^{b}\right)^{\gamma} \\
c_{t}+\left[\bar{k}_{t+1}-(1-\delta) \bar{k}_{t}\right]+\left[\bar{k}_{t+1}^{b}-\left(1-\delta_{B}\right) \bar{k}_{t}^{b}\right]=A_{t} F\left(\bar{k}_{t}, \bar{n}_{t}^{d}\right) \\
n_{t}^{s}=\bar{n}_{t}^{d}+\bar{n}_{t}^{b}
\end{gathered}
$$

Tel. 217938638, Fax 217940042, E-mail: dinamia@iscte.pt, Internet: www.dinamia.iscte.pt 
General Equilibrium with Banks and the Factor Intensity Condition

$$
\begin{gathered}
z_{t+1}^{\text {bank,l}}=\frac{1}{H} \\
\text { for } t=0,1,2,3, \ldots
\end{gathered}
$$

where $\lambda_{t}$ is a Lagrangean multiplier, $w_{t}$ is the real wage, $\tilde{p}_{t+1}$ is the rate of inflation between period $\mathrm{t}$ and period $(\mathrm{t}+1), R_{t}$ is the interest rate on bank loans, $b_{t+1}$ is borrowing per household in real terms, $z_{t+1}^{f}$ is the share of firm f owned by each household, and $z_{t+1}^{b a n k, l}$ is the share of bank 1 owned by each household. $\mathrm{H}$ is the number of households. $\beta$ is a discount factor $(0<\beta<1)$ that reflects a preference for current over future consumption-leisure bundles. $\delta_{B}$ is the rate of depreciation of the banks' capital stock and $\delta$ is the rate of depreciation of the firms' capital stock. The operator $E_{t}[$.$] yields the mathematical expectation of the indicated argument. u_{1}($,$) denotes$ the partial derivative of $u\left(c_{t}, 1-n_{t}^{s}\right)$ with respect to its first variable. Variables with a bar on top are per household variables.

Equations (1)-(4) have their origin in the typical household's first order conditions. Equations (5) and (6) have their origin in the typical firm's first-order conditions. Equations (7) and (8) have their origin in the typical bank's first-order conditions. Equations (9)-(13) are the market clearing conditions. There are two exogenous variables $\left(A_{t}\right.$ and $\left.D_{t}\right)$ and thirteen endogenous variables. The firm's production function and household's utility function used were $A_{t} F\left(k_{t}, n_{t}^{d}\right)=$ $A_{t}\left(k_{t}\right)^{1-\alpha}\left(n_{t}^{d}\right)^{\alpha}$ and $u\left(c_{t}, \ell_{t}\right)=\ln c_{t}+\phi \ln \left(1-n_{t}^{s}\right)$

To look at the response of the model (1)-(13) to shocks in the exogenous variables $\left(A_{t}\right.$ and $\left.D_{t}\right)$, we log-linearize each of the equations around the steady-state value of its variables and then use the method of King, Plosser and Rebelo (1988) which is based on Blanchard and Khan (1980).

ISCTE - Instituto Superior de Ciencias do Trabalho e da Empresa, 
General Equilibrium with Banks and the Factor Intensity Condition

\section{The Factor-Intensity Condition}

Since there are two sectors that both use capital and labour, there is a (capital / labour) ratio for each sector: $\left(k_{t} / n_{t}^{d}\right)$ in the case of the output sector; and $\left(k_{t}^{b} / n_{t}^{b}\right)$ in the case of the banking sector. The ratio between these two ratios is known as the factor-intensity condition.

In our study of the dynamic properties of this type of models, we always start from the steadystate of the model. On the other hand, because of the linearization, our analysis is only valid around the steady-state. Hence, we are specially interested in knowing the value of the factor-intensity condition in the steady-state. Using the equations that correspond to the first-order conditions of the firms' problem and first order conditions of the banks' problem [equations (5), (6), (7) and (8)], it is possible to show that, in the steady-state, the factor-intensity condition is given by

$$
\frac{\left(k / n^{d}\right)}{\left(k^{b} / n^{b}\right)}=\frac{1-\alpha}{\alpha} * \frac{\gamma}{1-\gamma} * \frac{r+\delta_{B}}{r+\delta}
$$

where $k$ is the firms' capital stock, $n^{d}$ is work hours in firms, $k^{b}$ is the banks' capital stock, $n^{b}$ is work hours in banks, $\alpha$ is the firms' Cobb-Douglas parameter, $\gamma$ is the banks' Cobb-Douglas parameter, $r$ is the real interest rate, $\delta_{B}$ is the rate of depreciation of the banks' capital stock and $\delta$ is the rate of depreciation of the firms' capital stock.

Using the values of $\alpha, \gamma, \delta_{B}, \delta$ and $r$ that were obtained by calibrating the model with U.S. data - see section 8 of Leao (2003) - we conclude that, in the steady-state, the value of the factor-intensity condition is

$$
\frac{\left(k / n^{d}\right)}{\left(k^{b} / n^{b}\right)}=0.19
$$

which means that in Leao (2003) the banking sector is the capital intensive sector. Small deviations from the steady-state are not strong enough to cause a reversal of this value of the factor-intensity condition.

ISCTE - Instituto Superior de Ciencias do Trabalho e da Empresa, 
General Equilibrium with Banks and the Factor Intensity Condition

Leao (2003) performs two types of impulse response experiments: a shock in the firms technological parameter $\left(A_{t}\right)$ and a shock in the banks technological parameter $\left(D_{t}\right)$. The results of the impulse response exercises - obtained with the factor-intensity condition (14) - are shown in figures 1 to 24 of Leao (2003) and are reproduced for convenience at the end of the present paper with the numbering (1a) to (24a). Note, in particular, that when a technological improvement occurs in banks, some capital and labour are transferred from banks to firms (figures 17a, 18a, 23a and 24a). The reason why this happens is as follows: when a technological improvement occurs in banks, the amount of credit that the banks can supply with their existing resources increases automatically (through the banks' production functions). However, bank credit in itself does not give utility to households. Bank credit only becomes useful if used to finance consumption. Therefore, some capital and labour are transferred from banks to firms to allow an increase in output that will permit consumption to rise along with bank credit (the more powerful technology in banks enables them to supply more credit even with fewer resources).

\section{Reversing the Factor-Intensity Condition}

The main goal of the present paper is to examine the role of the factor-intensity condition in the model of Leao (2003). To do this, we reverse the factor-intensity condition so that the banking industry ceases to be the capital intensive industry and becomes the labour intensive industry.

We can change the factor-intensity condition by changing the values used for $\alpha, \gamma, \delta_{B}, \delta$ and/or $r$. We did several experiments and the main conclusions can be illustrated using the following example. If we use $\gamma=0.78$ and take into account the implied change in the calibrated $\delta_{B}$, then the factor-intensity condition becomes 3.01. The impulse response results obtained with this 
General Equilibrium with Banks and the Factor Intensity Condition

factor-intensity condition are shown in figures (1b) to (24b). We can see that in general - when compared to figures (1a) to (24a), which are the results of Leao (2003) - the results do not change qualitatively although they change quantitatively. In particular, the results we obtain with a $1 \%$ technological shock in firms (1\% shock in A) are approximately the same as before. The variables more affected are the variables directly related to the banking system. On the other hand, the results we obtain with a $1 \%$ technological shock in banks (1\% shock in D) show the same pattern as before but change in quantitative way (the response is, in general, less pronounced).

We conclude that, in general, the qualitative results do not change when the banking industry ceases to be the capital intensive industry and becomes the labour intensive industry. There is, however, one interesting qualitative change: the response of the real wage and of the labour supply to a technological improvement in banks. If we ignore period 2 (which is the period where the shock occurs and hence is different from the following periods because capital cannot adjust), we can see that the effect on those two variables of a technological innovation in banks is the opposite of the results we have in Leao (2003): the real wage falls and the labour supply also falls (compare figure $16 \mathrm{a}$ to figure $16 \mathrm{~b}$ and figure $21 \mathrm{a}$ to figure $21 \mathrm{~b})$. Let us try to explain why this happens. We have seen that when a technological improvement occurs in banks there is a transfer of capital and labour from banks to firms. When the banking sector is the labour intensive sector, it will release relatively more labour than capital (when compared with the case where the banking sector is the capital intensive sector). This stronger release of work hours will exert downward pressure on the real wage and this will make the labour supply fall. The conclusion to be drawn is that the factor-intensity condition does play a role in the model.

ISCTE - Instituto Superior de Ciencias do Trabalho e da Empresa, 


\section{Why are the responses of sectoral outputs not dependent upon the factor-intensity condition?}

The interpretation we have just provided is typical of Heckscher-Ohlin models. There is however one notable difference between our results and the typical $\mathrm{H}-\mathrm{O}$ results. In the $\mathrm{H}-\mathrm{O}$ framework, the changes of sectoral outputs often depend upon the factor-intensity condition. By contrast, in the two-sector and two-factor model we are looking at, the qualitative nature of results regarding the changes in real output and in bank credit do not depend on the factor-intensity condition (when a technological innovation occurs in one sector, output always rises in both sectors). Let us try to explain why.

\subsection{The Heckscher-Ohlin framework}

In the Hecksher-Ohlin framework, the response of the sectoral outputs to exogenous shocks may depend on the factor-intensity condition, even in a closed economy. For example, an increase in the endowment of capital may lead to an increase in the output of the capital intensive sector and to a reduction in the output of the labour intensive sector. In fact, an increase in the endowment of capital leads to a reduction in the price of capital relative to the price of labour. As a result, there is a reduction in the relative marginal cost and therefore in the relative price of the capital intensive good. This raises the demand for this good at the expense of the demand for the labour intensive good. The price effect of an increase in the endowment of capital is thus an increase in the output of the capital intensive sector at the expense of the output of the labour intensive sector. Of course, the increase in the capital endowment also increases the wealth of the economy, and this positive wealth effect increases the demand and output in both sectors. Hence, an increase 
General Equilibrium with Banks and the Factor Intensity Condition

in the endowment of capital leads to a reduction in the output of the labour intensive sector only if its negative price effect on this sector is greater than its positive wealth effect ${ }^{1}$.

In an analogous way, in the Hecksher-Ohlin framework a neutral technological improvement in (for example) the capital intensive sector may lead to an increase in the output of this sector and a reduction in the output of the labour intensive sector. In fact, a technological improvement in the capital intensive sector reduces the relative marginal cost and therefore the relative price of the capital intensive good. This raises the demand and output of this good at the expense of the demand and output of the labour intensive good. Obviously, the technological improvement also increases the wealth of the economy, and this wealth effect increases the demand and output in both sectors. Therefore, a technological improvement in the capital intensive sector leads to a reduction in the output of the labour intensive sector only if its negative price effect on this sector is greater than its positive wealth effect.

The same results are obtained, mutatis mutandis, for the effect of an increase in the endowment of labour and for a neutral technological improvement in the labour intensive sector.

\section{$5.2 \quad$ The model of Leao (2003)}

In the model of Leao (2003), the response of sectoral outputs to exogenous shocks does not depend on the factor intensity condition. We can see in figures $1 \mathrm{a}, 2 \mathrm{a}, 13 \mathrm{a}, 14 \mathrm{a}, 1 \mathrm{~b}, 2 \mathrm{~b}, 13 \mathrm{~b}$ and $14 \mathrm{~b}$ that whenever a technological improvement occurs in one sector, output rises in both sectors (note that the output of the banking sector is bank credit in real terms which, in this model, corresponds to consumption in real terms). The reason for these results is as follows.

\footnotetext{
${ }^{1}$ In a small open economy, a stronger assertion is true. According to the Rybczinsky Theorem, an increase in the endowment of capital always leads to an increase in the output of the capital intensive sector and to a reduction in the output of the labour intensive sector.
}

ISCTE - Instituto Superior de Ciencias do Trabalho e da Empresa, Page: 11 Avenida das Forcas Armadas, 1649-026 Lisboa, Portugal, Tel. 217938638, Fax 217940042, E-mail: dinamia@iscte.pt, Internet: www.dinamia.iscte.pt 
General Equilibrium with Banks and the Factor Intensity Condition

When a technological improvement occurs in nonbank firms, output increases automatically (through the firms' production functions). More output will translate into higher utility levels by an increase in consumption. However, this increase in desired consumption can only materialize if there is an increase in the supply of bank credit that allows households to buy more consumption goods (the increase in bank credit is obtained by an increase in work hours in the banking industry). Note that the qualitative nature of the changes of sectoral outputs implied by this shock in the nonbank firms' technology is the same (increase in output and increase in bank credit) irrespective of which sector is capital intensive.

On the other hand, as already mentioned, when a technological improvement occurs in banks, the amount of credit that the banks can supply with their existing resources increases automatically (through the banks' production functions). However, bank credit in itself does not give utility to households. Therefore, some capital and labour are transferred from banks to firms to allow an increase in output that will permit consumption to rise along with bank credit (the more powerful technology in banks enables them to supply more credit even with fewer resources). Note that the qualitative nature of these changes of sectoral outputs (increase in output and increase in bank credit) does not depend on which sector is capital intensive.

\subsection{Rationalization}

We may rationalize as follows. Although the model of Leao (2003) has the basic Heckscher-Ohlin features - two sectors and two factors of production -, there is one important difference between his model and the standard Heckscher-Ohlin framework. In Leao (2003), the output of the banking sector is bank credit and bank credit in itself does not give utility to households. The only use of bank credit is to finance consumption (which in his model corresponds to over $80 \%$ of total 
General Equilibrium with Banks and the Factor Intensity Condition

output). On the other hand, if they wish to increase consumption, households must borrow from the banks; and so the banking sector can be seen as an "intermediate sector" that produces an input - credit -which is necessary for the other sector to be able to sell its output. This means that the production of the two sectors is not independent in Leao (2003): it is not possible to increase consumption without raising the supply of bank credit; and it does not make sense in economic terms to increase the supply of bank credit without an increase in consumption. In the Heckscher-Ohlin framework, we have two goods which directly affect the households' utility and there is no complementarity whatsoever between the two sectors. Therefore, it is perfectly possible for the output of one sector to rise while the output of the other sector falls.

\section{Conclusion}

Leao (2003) builds a model with two sectors: output sector and banking sector. We have looked at how the impulse response results from his model are affected by reversing the factor-intensity condition. We have concluded that, with two exceptions, the qualitative nature of the results is not affected. In particular, when a technological shock occurs in one sector, output rises in both sectors.

The only cases where the impulse response results are reversed are the response of the real wage and of the labour supply to a shock in the banks technological parameter. We have provided an interpretation based on the framework devised by Heckscher and Ohlin.

The results we obtained confirm that the factor-intensity condition plays an important role in the model of Leao (2003). This role is however less important than it is in the Heckscher-Ohlin framework.

ISCTE - Instituto Superior de Ciencias do Trabalho e da Empresa, 
General Equilibrium with Banks and the Factor Intensity Condition

\section{References}

[1] Blanchard, O. and Khan, C. (1980). The solution of linear difference models under rational expectations. Econometrica 48: 1305-1311.

[2] Hansen, G. 1985. Indivisible labor and the business cycle. Journal of Monetary Economics 56: 309-327.

[3] King, R., Plosser, C. and Rebelo, S. (1988). Production, growth and business cycles: I. The basic neoclassical model. Journal of Monetary Economics 21: 195-232.

[4] Kydland, F. and Prescott, E. (1982). Time to build and aggregate fluctuations. Econometrica 50: $1345-1370$.

[5] Leao, E. (2003). A dynamic general equilibrium model with technological innovations in the banking sector. Journal of Economics (Zeitschrift für Nationalökonomie) 79: 145-185.

[6] Long, J. and Plosser, C. (1983). Real Business Cycles. Journal of Political Economy 91: 39-69.

[7] Rybczynski, T. (1955). Factor endowment and relative commodity prices. Economica 22: 336341.

ISCTE - Instituto Superior de Ciencias do Trabalho e da Empresa, 

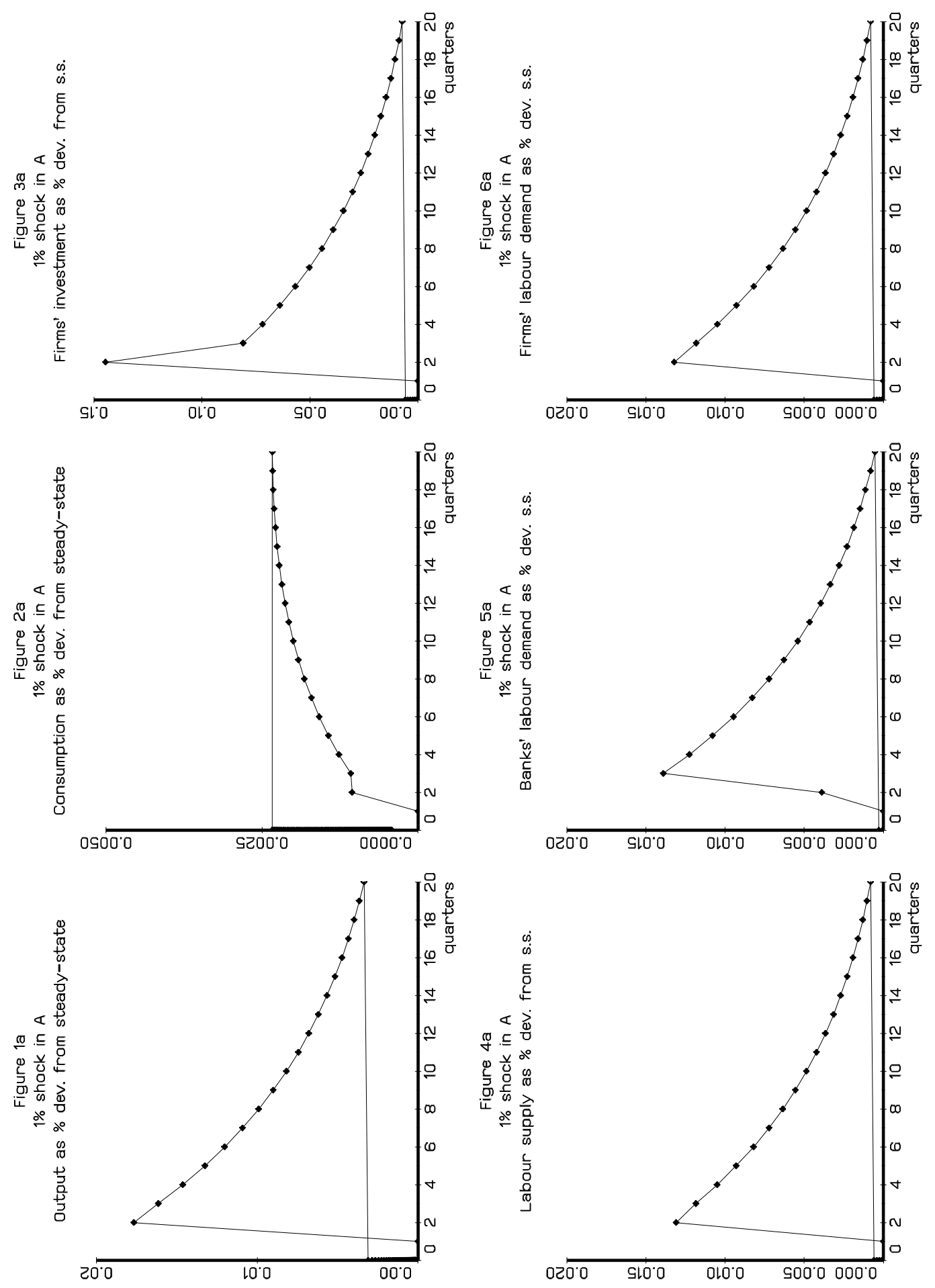

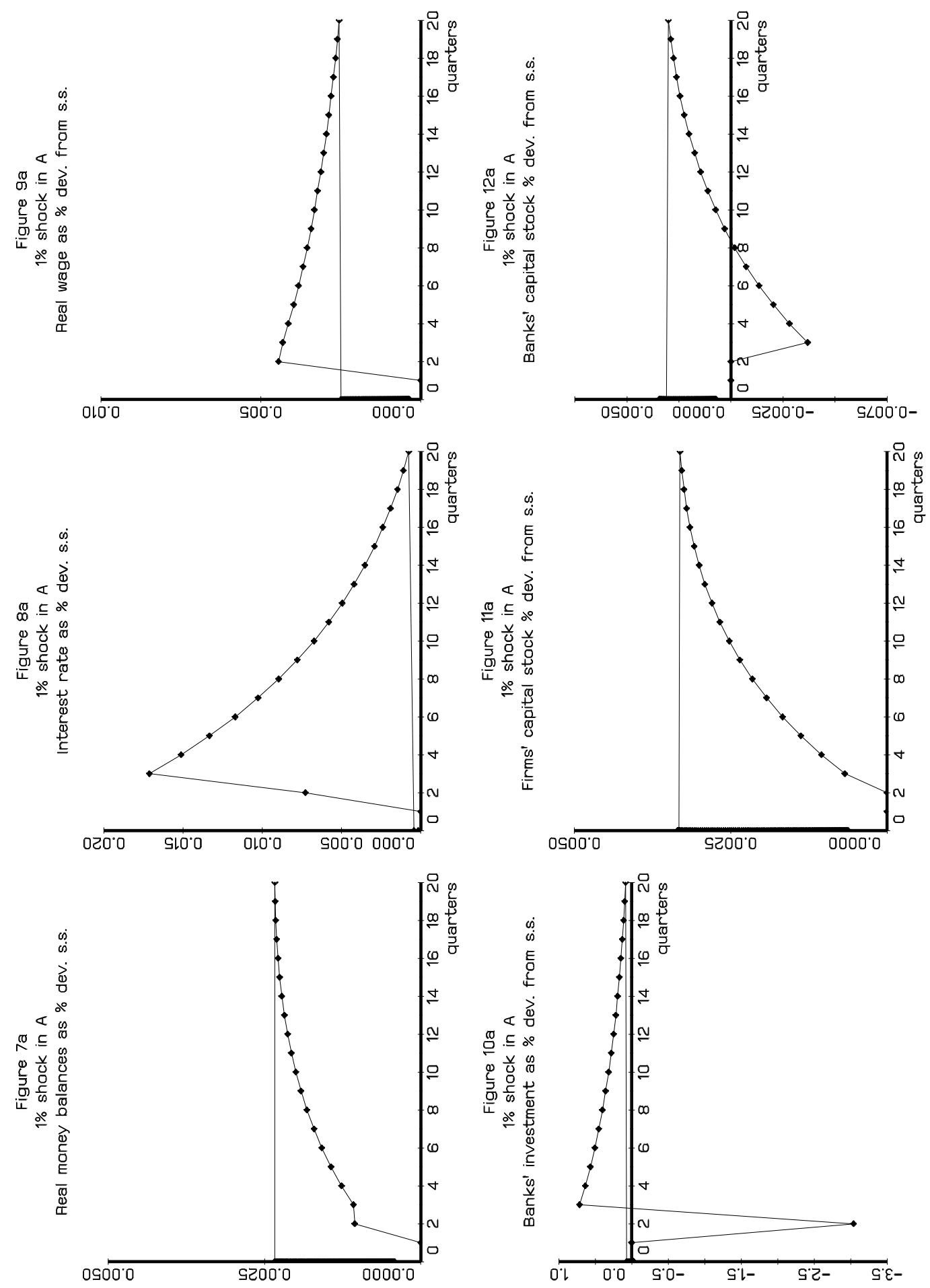

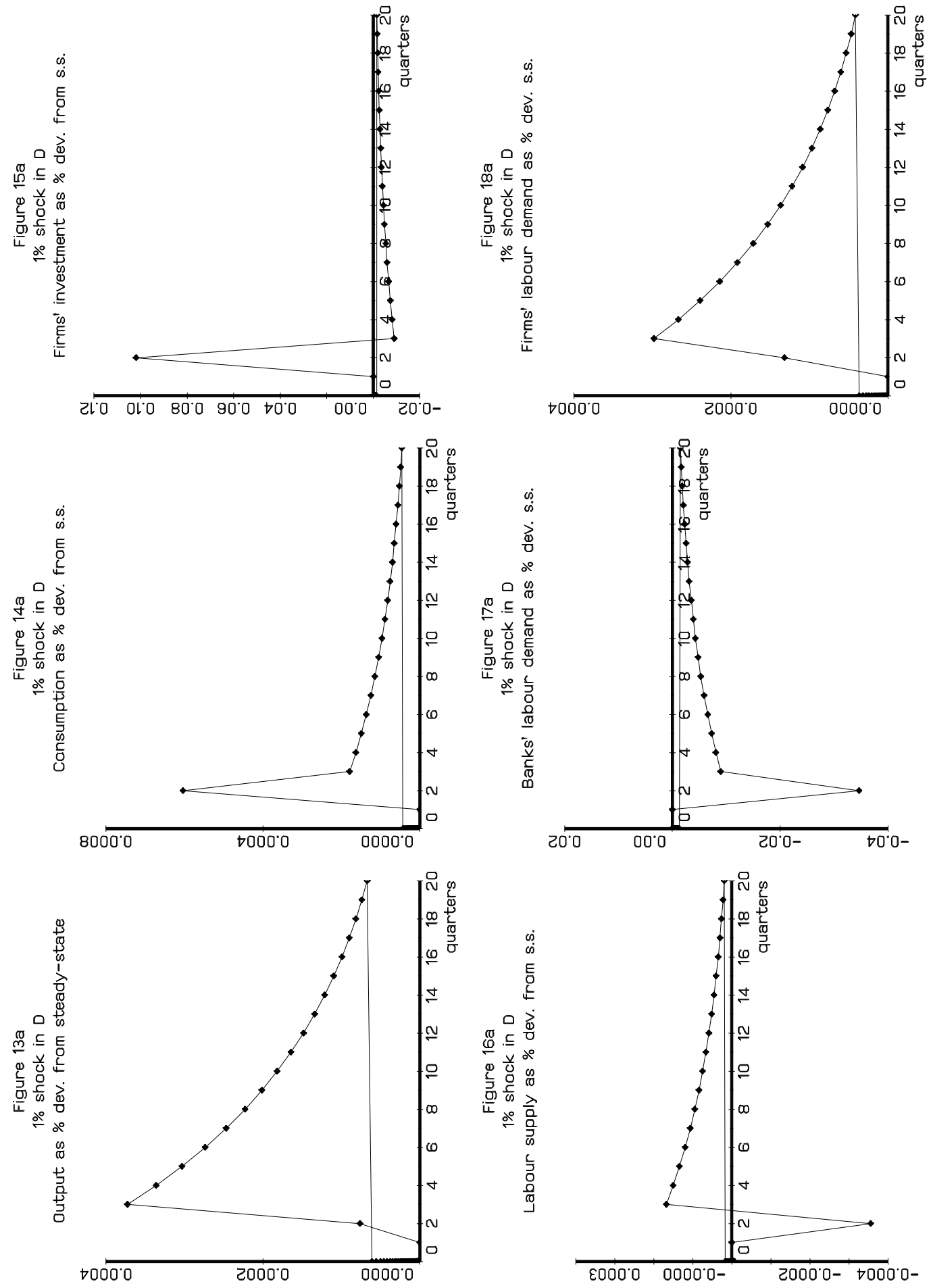

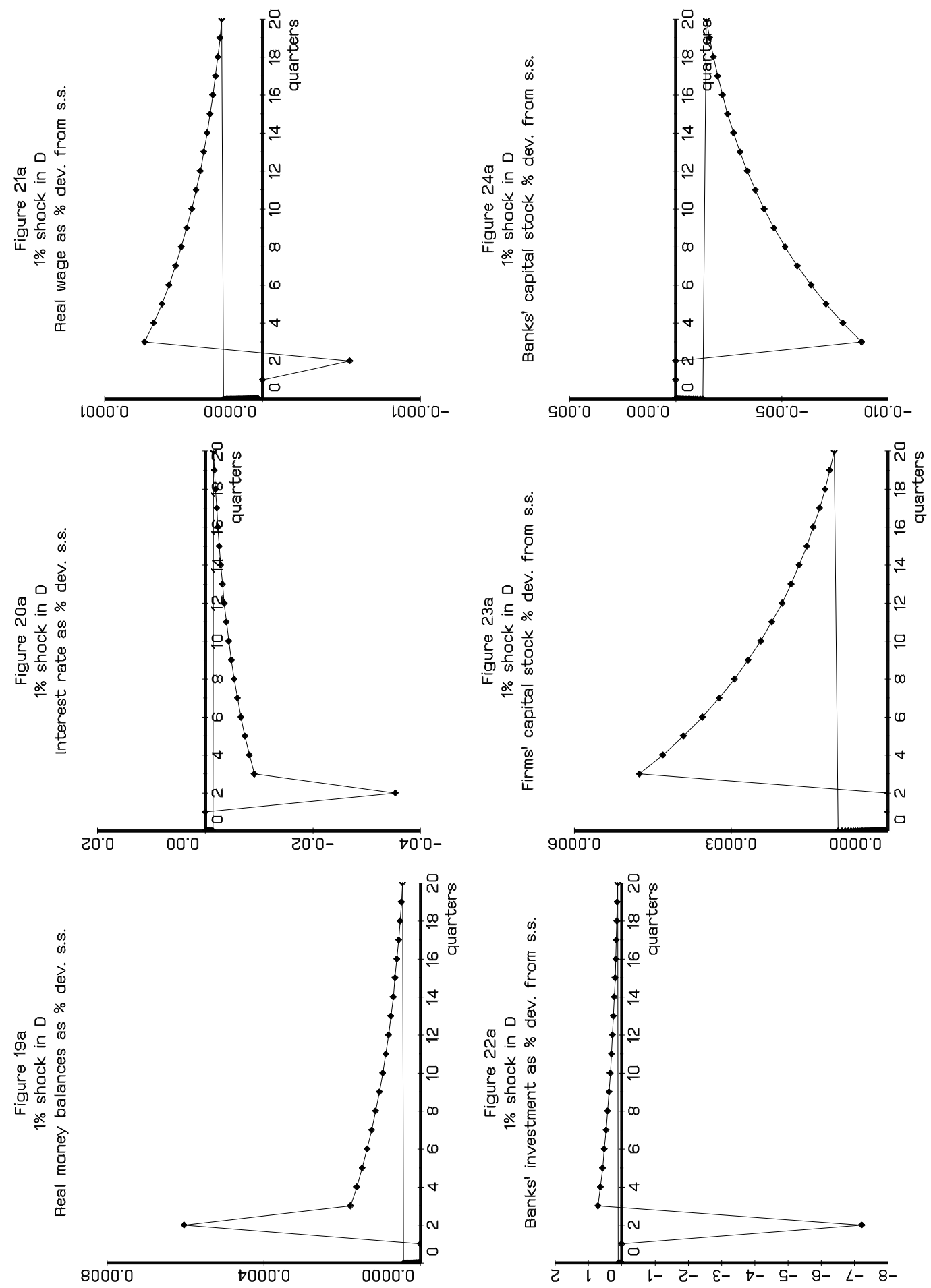

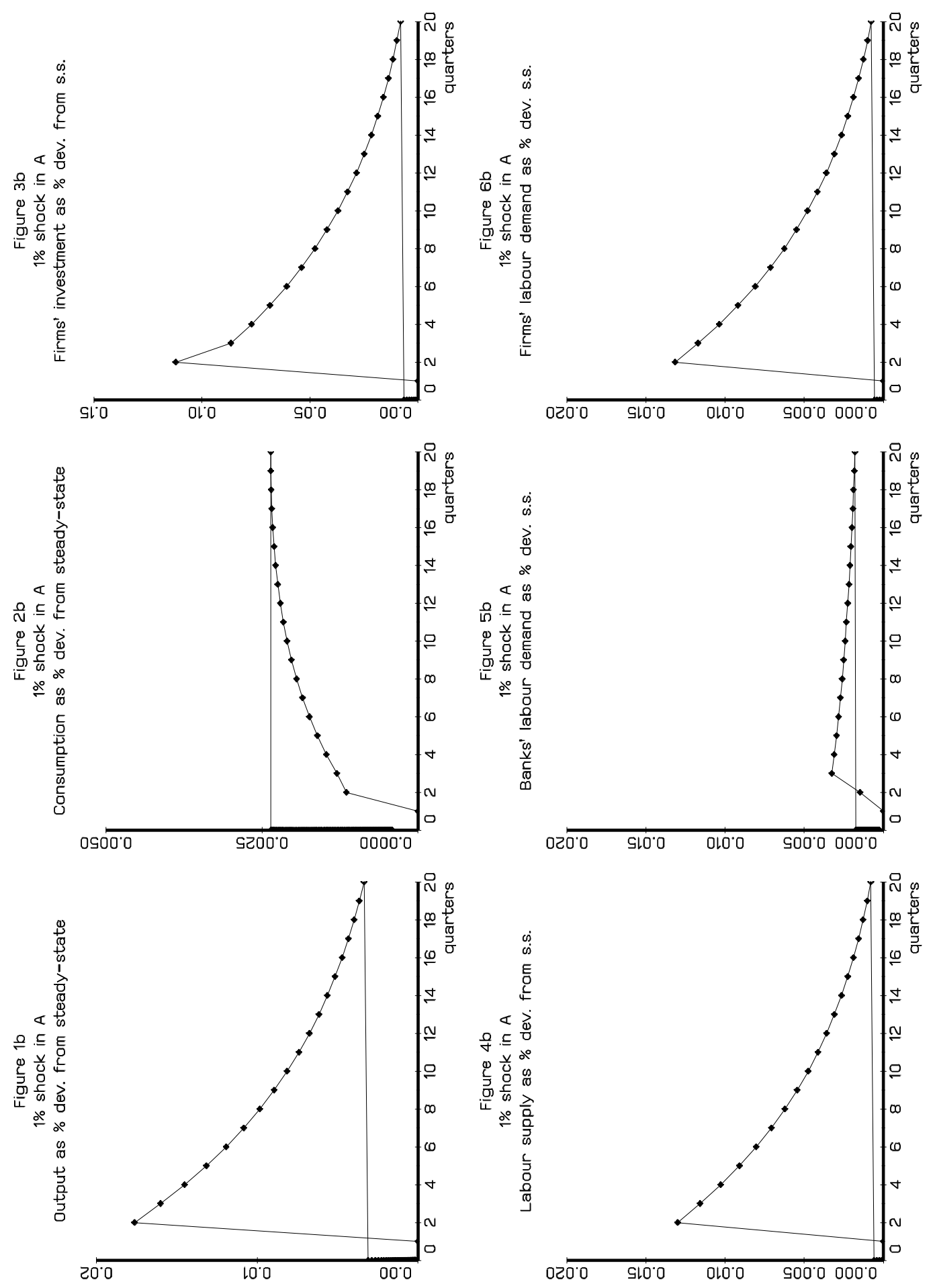

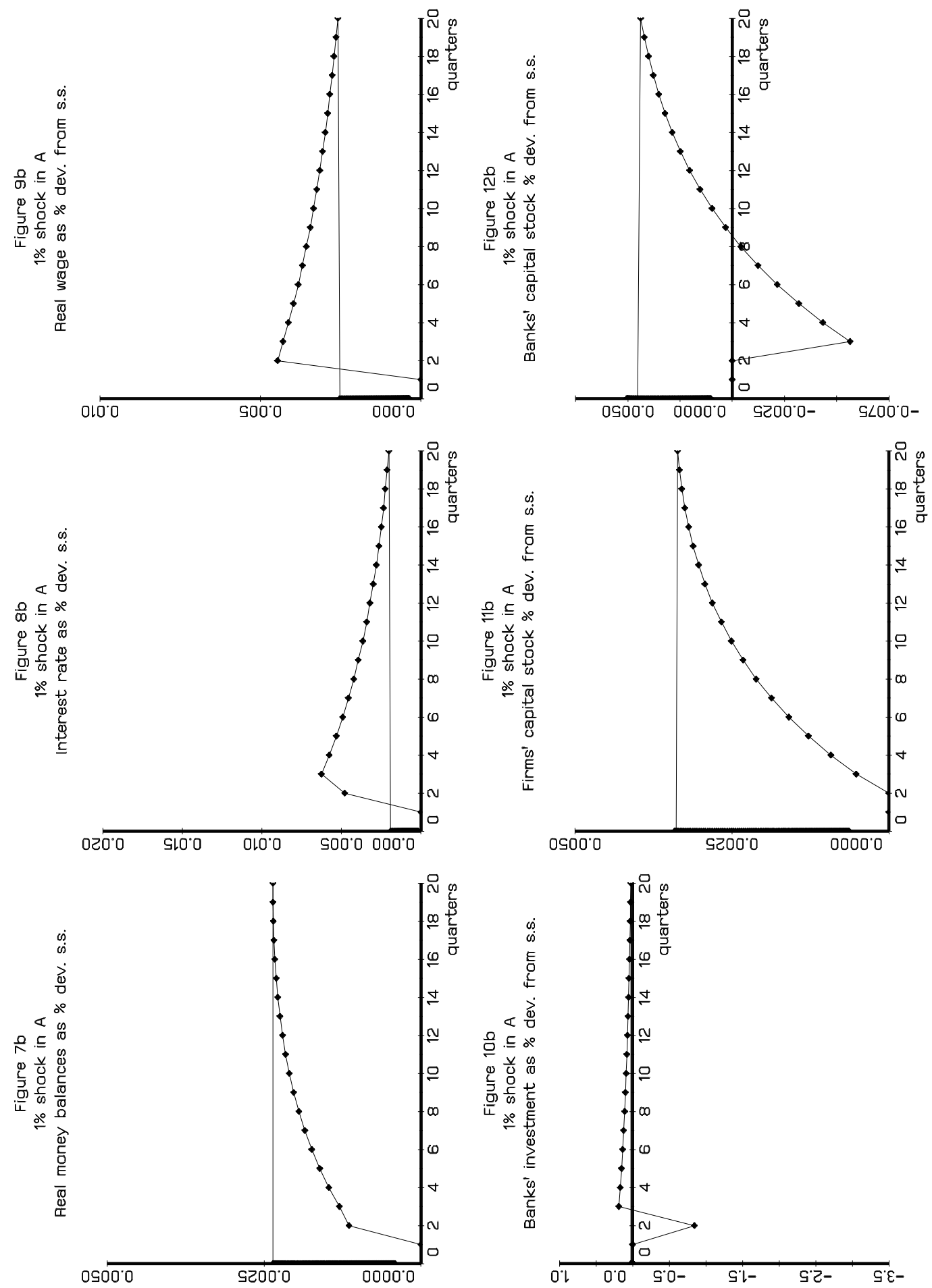

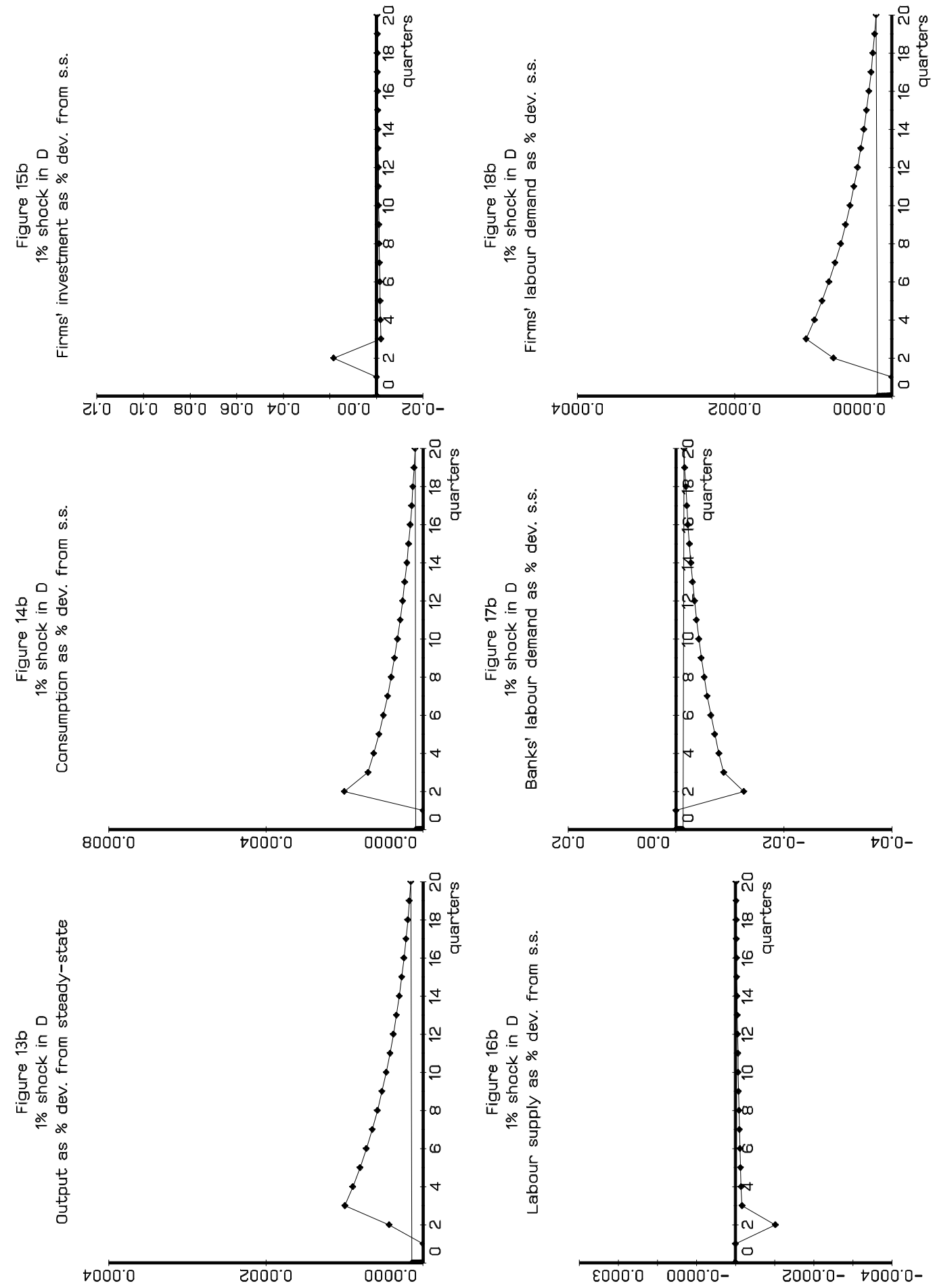

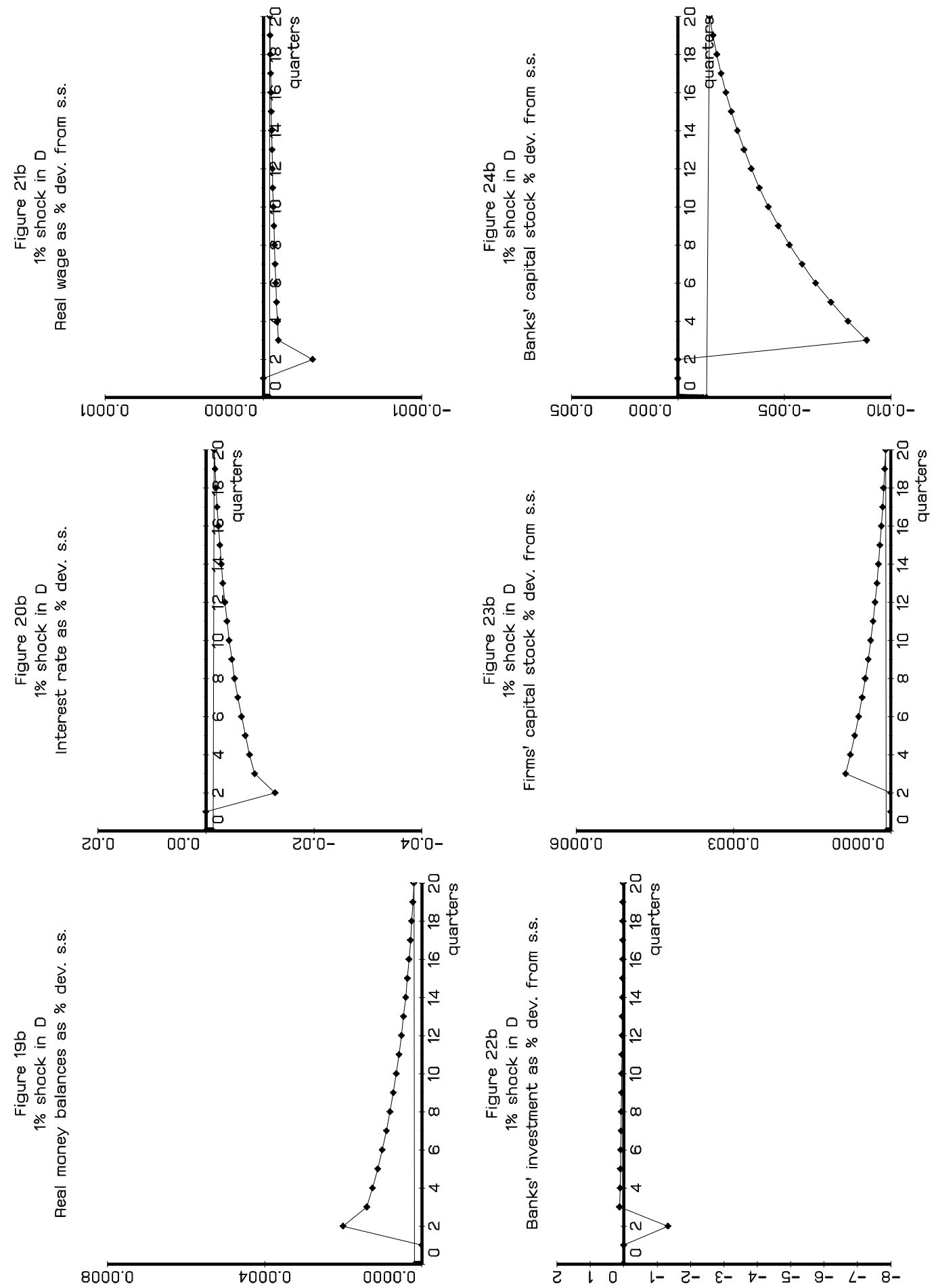